Revista Iberoamericana, Vol. LXXVI, Núm. 231, Abril-Junio 2010, 393-407

\title{
POLÍTICA CULTURAL Y EUROCENTRISMO EN EL MIEDO A LOS ANIMALES DE ENRIQUE SERNA
}

POR

Hugo MÉndez-RamíREZ

To write about the histories of the tricontinental countries, the three continents of the south, is to write about the lapses of history itself. Of spaces blanked out by that ruthless whiteness. (...)

It was never the case that the subaltern could not speak: rather that the dominant would not listen.

Robert Young, White Mythologies

La relación entre los intelectuales y el Estado en México ha sido generalmente una relación de conveniencia y mutuo entendimiento. La famosa frase "vivir fuera del presupuesto es vivir en el error" nos remite de inmediato a ciertos espacios culturales que, con pocas excepciones, han sido cooptados para ejercer una defensa sutil o explícita de las formas establecidas de poder. Desde luego que esta relación entre Estado y productor cultural no es nada nuevo. Lo que sí es nuevo, sin embargo, es la convicción de que una nación con un sólido programa de apoyo cultural es una nación fuerte, cuya imagen y prestigio en el exterior puede redituar en múltiples beneficios políticos y económicos. No es hasta 1945 que muchas naciones se dan cuenta de la necesidad de preservar la herencia cultural del pasado, promover la participación cultural del presente y desarrollar nuevos logros artísticos culturales para el futuro. Desde luego que los programas de hoy han sido sustancialmente reestructurados con el objeto de presentar la transición de un gobierno aburguesado o aristocrático a uno más democrático o popular (Cummins y Katz 8). ${ }^{1}$ El objetivo es solidificar la noción dentro y fuera del país de que México es una nación moderna.

1 Lo anterior es señalado por Cummins y Katz en su libro, The Patron State. Debo agregar que si bien es cierto que el estudio de Katz y Cummins se concentra en los países europeos, EE.UU., Canadá y Japón, también es cierto que dicha tendencia a la democratización del producto cultural por parte del Estado, también es común a casi todos los países de Latinoamérica, incluyendo México. 
En México, la política cultural ha estado signada por un complejo sistema de negociaciones que obedece fundamentalmente a ese insistente afán por alcanzar la modernidad, y en cuyo sustrato se encuentra un imaginario nacional históricamente moldeado de acuerdo a un discurso eurocéntrico que obviamente tiene que ver con diferencias de clase, pero que está íntimamente ligado a cuestiones de raza, origen étnico y género. Mi propósito aquí, en todo caso, es examinar desde la perspectiva de algunos recientes estudios culturales y poscoloniales la compleja dinámica del poder en la producción cultural del país a través de la lectura de dos novelas que tratan el tema de la política cultural en México y que nos sirven como espacios de conocimiento y análisis. Una es la novela experimental de Luis Guillermo Piazza, titulada La mafia y que fue publicada en los años sesenta; y la otra es El miedo a los animales de Enrique Serna, publicada en 1995, y en la cual nos concentramos especialmente por el interesante uso que hace el autor del género de la novela negra para describir el mundo de los escritores.

En los últimos cinco años hemos visto desde, diferentes espacios discursivos un creciente interés por el tema de la política cultural tanto en México como en Latinoamérica, en general. Así lo demuestran la serie de estudios académicos, el gran número de disertaciones escritas en los últimos dos años y los simposios y congresos organizados en torno al tema, incluso algunos proyectos e iniciativas gubernamentales y de ONGs. Voy a mencionar sólo algunos. En 2001, la Revista Iberoamericana dedicó un volumen especial titulado, "Mercado, editoriales y difusión de discursos culturales en América Latina”. El número contiene una serie de valiosos estudios por distinguidos académicos del campo, entre ellos, George Yúdice, Raúl Antelo y María Eugenia Mudrovcic. La Universidad Autónoma Metropolitana publicó en 2004 una serie de trabajos presentados en el Simposio "Reabrir espacios públicos: políticas culturales y ciudadanía”, realizado en 2001, en el cual participaron varios intelectuales de la cultura, tales como Néstor García Canclini (coordinador) y Roger Bartra, entre otros.

Anteriormente (1999-2000), el Convenio Andrés Bello de Colombia, un organismo internacional e intergubernamental, convocó a varios intelectuales de Latinoamérica a participar en un proyecto de integración cultural en Latinoamérica. Los resultados de estas dos reuniones de trabajo fueron publicados más tarde, en 2003, por el Fondo de Cultura Económica, con el título El espacio cultural latinoamericano. Bases para una política cultural de integración. En este sentido, la profesora Jill Robbins, en su artículo, “Globalization, Publishing, and the Marketing of 'Hispanic' Identities”, examina los paradójicos efectos de la globalización en España y Latinoamérica a través de los grandes conglomerados editoriales del producto cultural y artístico, así como la consiguiente desarticulación de la relación editor-escritor o el final del libro como forma de resistencia y solidaridad. Más específicamente, Deborah Cohn publicó en 2005 un valioso estudio sobre el mundo

Revista Iberoamericana, Vol. LXXVI, Núm. 231, Abril-Junio 2010, 393-407
ISSN 2154-4794 (Electrónico) 
intelectual mexicano y su impacto en la vida cultural de México entre 1950 y 1968, la llamada "Generación de medio siglo". El artículo es un excelente análisis de la dinámica cultural de estos años y de sus figuras más sobresalientes e influyentes. Casi diez años antes, desde luego, el estudio de Danny Anderson, “Creating Cultural Prestige: Editorial Joaquín Mortiz”, metodológicamente hablando, fue uno de los primeros estudios en la academia estadounidense sobre las publicaciones y casas editoriales.

En general, la aproximación al estudio de la política cultural ha estado bajo la lupa de la crítica literaria y se ha reservado más al género ensayístico y de análisis, aunque a veces dichos estudios sean hechos por los mismos escritores o artistas. Tal es el caso de Gabriel Zaid, Luis Arturo Ramos, Carlos Fuentes, Celso Santajuliana, Mempo Giardinelli y otros más. Resulta, por lo tanto, de lo más interesante que el tema de la cultura en México sea abordado en forma novelada por Enrique Serna bajo la rúbrica de la novela negra. Publicada en 1995, El miedo a los animales es la primera novela en México que ha sido dedicada plenamente a capturar el zeitgeist de la vida intelectual. ${ }^{2}$

Mucho antes de la novela de Serna, Luis Guillermo Piazza, un escritor poco conocido hoy, publicó en 1967 una curiosa novela que lleva el sugestivo título de La mafia. Escrita más o menos al estilo híbrido experimental de José Agustín y los escritores de "La Onda," la obra es un verdadero collage de acontecimientos, experiencias, conversaciones, cartas, folletos y anécdotas -algunas narradas por los mismos protagonistas-de un grupo de escritores, artistas e intelectuales, conocidos en el ámbito intelectual como "La Mafia”, y que dominaron el espacio cultural en México durante los años sesenta. Más que novela, se trata de un ensayo novelado, experimental y caótico, cuya coherencia y unidad giran en torno al mito de este influyente grupo y de algunas de sus figuras principales. Una de estas figuras es Fernando Benítez, fundador y director del suplemento cultural México en la cultura de 1949 a 1961; y luego, a partir de 1965, fundó y dirigió La cultura en México. Otras figuras representadas en la novela son Carlos Fuentes, Carlos Monsiváis, el pintor José Luis Cuevas, Octavio Paz, Alí Chumacero, Inés Arredondo, Juan García Ponce, Rosario Castellanos, Emilio Carballo, así como otros miembros de la "Generación de Medio Siglo", quienes controlaban los espacios de producción cultural en México durante esta época y se proponían a favor de una orientación cosmopolista y universalista del arte. Como bien señala Deborah Cohn, el cambio de nombre del suplemento cultural dirigido por Benítez correspondió al cambio de orientación (“Construcción” 93). Más que una crítica el monopolio cultural que

2 En los Estados Unidos apareció en 1993 Murder at the MLA de D. J. H. Jones, una novela de tema similar que tiene lugar en Chicago durante la Conferencia Anual de la Modern Language Association, durante la cual mueren misteriosamente varias figuras de la academia estadounidense.

\footnotetext{
Revista Iberoamericana, Vol. LXXVI, Núm. 231, Abril-Junio 2010, 393-407 ISSN 0034-9631 (Impreso) ISSN 2154-4794 (Electrónico)
} 
ejercía este grupo, la “novela” es la reafirmación y la confirmación de esta Mafia, cuya razón de ser -con su esnobismo y elitismo- se justifica estéticamente por considerarse ellos los garantes de la calidad de la producción cultural en el país. Una especie de policía de la cultura.

[...] Revisémonos los unos a los otros. La gran aportación de la TRINIDAD a México es que por primera vez hay un grupo crítico dispuesto a dar todo su elogio y toda su crítica según y a como la obra lo amerite y ya no a partir del cachondeo cuatachista o de la repugnancia hacia el color de las corbatas y el olor de las lavandas. (Piazza 54)

El epígrafe de la novela resume muy bien lo anterior:

Mafía: término que en Italia o USA implica cierta asociación de índole más bien criminal, y que en México, por extraño símil, se aplica preferentemente a un supuesto confuso misterioso grupo de regidores de la cultura, al que todos atacan y al que todos ansiarían pertenecer. (7)

El famoso pintor mexicano, José Luis Cuevas, quien defendía la idea de derrumbar "la cortina de nopal” desde Madrid, le manda a Piazza una carta escrita en un folleto promocional de su obra en esa ciudad, justificando la existencia de La Mafia:

Creo que te conté que me entrevistaron para NewsWeek [...]. En esta entrevista digo todo lo que me molesta y también mencioné a los artistas que admiro. De ti hablé y de Carlos Fuentes. Por cierto que me han llegado rumores de que tú eres el inventor de la "Maffia" a la que me honro pertenecer. Creo yo que debemos crear un círculo muy cerrado y no permitir el paso a los mediocres. Creo además que debemos echar [sic] a algunos que se han colado. (Piazza, sn, le sigue a la página 56)

Aunque a veces Piazza parece rechazar la crítica fratricida y destructiva en México, también parece justificarla cuando acepta que ésta es preferible al anonimato o la indiferencia. La nota constante de este documento es, por un lado, la defensa del esnobismo aburguesado de la Zona Rosa con sus espacios exclusivos y, por el otro, el rechazo total del ámbito chocante tercermundista que coexiste simultáneamente con El Café, las galerías de arte, los anticuarios, La Librería. La hibridez del texto está marcada también por el uso e interpolación de frases y hasta párrafos completos en inglés o francés que funcionan no como un recurso artístico incluyente, multicultural o multilingüe, sino como una forma más de distanciamiento

Revista Iberoamericana, Vol. LXXVI, Núm. 231, Abril-Junio 2010, 393-407 
cultural del entorno local que apunta, y señala al mismo tiempo, hacia la creciente influencia de la cultura estadounidense en México. ${ }^{3}$

La importancia de este texto radica precisamente en su visión desde dentro del fenómeno cultural. Sin candor ni pudor, Piazza no intenta, como sugiere la contraportada del libro, "una desmitificación de 'La Mafia' en cuanto a supuesta Intelligentsia conspiradora, todopoderosa, orgiástica y con rígidas consignas”. Por el contrario, el texto sirve para legitimar la existencia de un grupo de escritores y artistas inconformes, como antes los contemporáneos, con el medio intelectual y la manera "tradicional" de hacer ficción. En este sentido, la novela de Piazza se convierte en el testimonio personal del autor y de su orgullosa adscripción a este grupo cosmopolista y universalista de México.

Casi treinta años después, aparece El miedo a los animales de Enrique Serna con un enfoque diametralmente opuesto al proyecto de Piazza. La novela de Serna también nos remite al interior del ámbito literario y cultural de México, pero no a un espacio iluminado y sublime, sino a un imaginario intelectual contaminado y corrompido por el poder, más al estilo de una verdadera mafia del crimen organizado o el mundo sucio de la política. No hay que olvidar que el referente político de la novela es el sexenio de Carlos Salinas de Gortari, un gobierno que se caracterizó por su fuerte apoyo a las artes, que fundó el Consejo Nacional para la Cultura y las Artes y promovió la creación de múltiples premios y talleres literarios por todo el país a través del INBA, FONCA, UNAM, y otras, pero que también se caracterizó por una serie de asesinatos políticos y culminó con la rebelión zapatista en Chiapas ante la implementación del TLCAN en 1994. ${ }^{4}$ Esto explica por qué el autor se vale del género de la novela negra para contar su historia. La mera selección del género es parte del comentario: la forma es el mensaje. Pero mientras que Paco Ignacio Taibo II, Manuel Vásquez Montalbán y otros utilizan el género de la novela negra para denunciar la bancarrota política y social del país, Serna lo adopta con el objeto de desenmascarar y denunciar la no menos perversa política cultural que define al mundo artístico y literario de México.

Escrita con humor corrosivo e ironía, la novela la toma contra todo y contra todos sin distinción. El miedo a los animales, subtitulada en la edición de Planeta Delirios y miserias de la fauna literaria, ofrece una cruel radiografía de una élite corrompida por un ciego afán de poder y supremacía de manera similar a la lucha

3 En los años sesenta la Casa de las Américas publicó un volumen especial dirigido por Roberto Fernández Retamar sobre la penetración intelectual del imperialismo yanqui en América Latina.

4 Como señala Deborah Cohn, el expresidente mexicano "in particular capitalized upon the ties linking intellectuals and the State by cultivating a coterie of intellectuals who would accompany him on his travels and by fostering good will by setting up a system of grants supporting artistic activity" (“Mexican Intelligentsia” 144).

Revista Iberoamericana, Vol. LXXVI, Núm. 231, Abril-Junio 2010, 393-407
ISSN 2154-4794 (Electrónico) 
por el poder que se da entre los políticos o el crimen organizado. El estilo policiaco facilita la denuncia y la acusación de los diferentes espacios que contribuyen a la corrupción del mundo intelectual: la hipocresía y corrupción de la prensa o el mundo mediático oficialista que recibe "subvenciones" del gobierno el famoso "chayote" a los periodistas, la arrogancia y esnobismo de los intelectuales de la "casta divina", los arribistas y advenidizos que consiguen plazas como agregados culturales en el servicio exterior, la soberbia, la prepotencia e ignorancia de los funcionarios públicos y las manipulaciones de premios y becas por jurados corruptos. Pero, sobre todo, la novela condena la hipocresía, la deslealtad y la falta de sinceridad de la fauna intelectual, pues estos defectos, según la tesis que propone el texto, son peores que la violencia de los judiciales o de los narcotraficantes ya que esta última violencia al menos es sincera.

La novela se inicia con el asesinato de Roberto Lima, un escritor marginal que trabaja en la sección cultural del periódico El matutino, donde frecuentemente incrustaba, entre sus comentarios, ataques directos al gobierno de Jiménez del Solar (Carlos Salinas de Gortari), tales como "chingue a su madre Jiménez del Solar" o "[Jiménez] traidor a México”. El crimen es investigado por Evaristo Reyes, exreportero y escritor frustrado que se convierte en policía judicial con el fin de escribir un día "un reportaje novelado al estilo de Truman Capote que pararía de cabeza el sistema político mexicano" (18). Antes del asesinato, guiado por una rara admiración al valor y coraje de Lima, Evaristo se propone ayudar a Lima, previniéndolo del peligro en que se encuentra, pues el aparato represivo de gobernación ya ha sido puesto en marcha para deshacerse de él. Para Evaristo, Lima representa el ideal del escritor comprometido, el escritor auténtico y fiel a sus convicciones que está dispuesto a sufrir las consecuencias de sus actos, y por esta razón decide ayudarlo a que huya, dejándole su pistola y una alta suma de dinero. Más tarde, al llegar a su oficina, Evaristo se encuentra con que Roberto Lima fue asesinado de un duro golpe en la nuca con un grueso diccionario de sinónimos y contrarios, minutos después de su visita, y que él es el principal sospechoso. Desde luego que Evaristo niega tener algo que ver con el asesinato de Lima y le pide a su jefe, el comandante Maytorena, que lo deje investigar el caso y descubrir quién es el verdadero asesino y los motivos del crimen.

La investigación lleva a Evaristo a internarse dentro del mundo intelectual de la fauna literaria. Poco a poco va descubriendo el sórdido mundo de una elite arrogante, prepotente e hipócrita que lucha por la supremacía cultural, y que es capaz de cualquier cosa con tal de alcanzarla. La caída de la venda o el clímax del desencanto ocurre cuando el protagonista descubre que aquellos escritores que él admiraba por ser “comprometidos" con las causas sociales, tales como Palmira Jackson (Elena Poniatowska), también sufren o padecen del mismo egocentrismo y megalomanía

Revista Iberoamericana, Vol. LXXVI, Núm. 231, Abril-Junio 2010, 393-407
ISSN 2154-4794 (Electrónico) 
de los demás. Esto lo descubre Evaristo cuando logra entrar en la casa de Palmira Jackson suplantando a un mesero contratado para el servicio de una recepción a los líderes campesinos, que momentos antes protestaban en el Zócalo, frente al Palacio de Gobierno. Inicialmente, el plan de Evaristo era convencer a Palmira Jackson de que le ayudara a esclarecer el crimen y a limpiar su nombre, pues a él se le acusaba en la prensa de ser el asesino de Roberto Lima y, peor aún, de estar al servicio de las fuerzas represivas del PRI y el gobierno. Durante la recepción, Evaristo llega a presenciar la arrogancia de la escritora, quien se rehúsa a compartir un panel con ciertos escritores y escritoras que no gozan de su aprobación o respeto intelectual. Como buena pontífice de la literatura testimonial y comprometida, Palmira nunca tiene palabras de admiración por ningún otro escritor o escritora, incluso para con sus mismos invitados que, tan pronto se dan la vuelta, son inmediatamente víctimas de sus incisivos y duros comentarios. El narrador desvela la corrupción de Jackson al notar su duplicidad e hipocresía, "Palmira era ahora un símbolo de la humanidad que lo había traicionado. El mundo entero estaba hundido en la corrupción, incluyendo a la gente que decía luchar contra ella” (229).

Finalmente, Evaristo es atrapado, encarcelado y sentenciado a prisión, en donde por fin escribe su deseada novela al estilo de Truman Capote y con la cual recibe un prestigioso premio literario de novela, "Eureka" organizado por la Editorial Quinto Sol. Curiosamente, el mentado premio literario recibido en la cárcel es el detonante del dénoument de la novela y del esclarecimiento del crimen. El asesino resulta ser Rubén Estrella, un escritor y supuesto amigo del difunto que había recibido varios premios, que tiene un puesto importante en el Instituto de Artes y Letras (CONACULTA) y que celoso ahora del éxito literario de Evaristo intenta asesinarlo a él también durante una visita aparentemente amistosa a la prisión. Descubrimos que el móvil del asesinato se debió al hecho de que Roberto Lima, íntimo amigo de Rubén Estrella, nunca escribió nada halagador sobre los éxitos y premios del asesino.

El Robert era incapaz de admirar a ningún amigo [...]. A mí no me atacaba porque éramos cuates, pero nunca le pude sacar un elogio. Le molestaban mis publicaciones, mis premios, mis entrevistas. Sencillamente me ignoraba en sus notas, como si yo no existiera. (262)

Con la publicación de la novela premiada, y después de esclarecido el crimen, Evaristo alcanza la fama y el renombre en los círculos literarios. Pero a pesar de que el gobierno le ofrece ahora becas y puestos en el aparato cultural del Estado, Evaristo prefiere abandonar ese ámbito y regresar al bajo mundo policiaco, al mundo de la realidad, porque, según el protagonista, "necesitaba respirar aire puro".

Revista Iberoamericana, Vol. LXXVI, Núm. 231, Abril-Junio 2010, 393-407
ISSN 2154-4794 (Electrónico) 
Es claro que la atípica incursión de Enrique Serna en el género negro es sólo un pretexto para poner en evidencia una serie de aspectos relacionados con la producción cultural del país durante un momento crítico de la vida nacional, y que a su vez nos sirve de pretexto para ahondar y acercarnos a la dinámica social de clase y raza que se vierte en estos textos, y que tiene que ver con la producción cultural.

A diferencia de Luis Guillermo Piazza, Enrique Serna sí intenta desmitificar el mundo cultural del país. Aunque lo que se presenta aquí es una visión esperpéntica y exagerada de la realidad cultural, la novela intenta de esta manera desmitificar y deconstruir ese espacio de la República de la Letras, considerado normalmente como un ámbito sublime que está por encima de las presiones y deseos mundanos del sistema. De esta forma, el supuestamente noble ejercicio de la escritura se convierte aquí en una actividad mezquina y egoísta, que sólo sirve como excusa o llave de acceso al poder. En realidad, la contribución más importante de Serna con esta novela, independientemente de sus méritos artísticos, es presentar la profunda crisis intelectual del país, la total bancarrota de la cultura y el completo fracaso del Estado en lograr una verdadera y auténtica democratización de la cultura.

Aunque el contexto de la novela, como ya señalamos, es el sexenio de Salinas de Gortari, la realidad reflejada aquí también se podría aplicar a la pasada administración de Vicente Fox, ya que ésta tampoco supo descentralizar, separar o aislar la política de la cultura. En julio de 2000, Vicente Fox, el entonces presidente electo, convocó a una reunión a la cual asistieron casi todas las grandes figuras de la cultura en México (aunque con las excepciones de esperar), tales como Carlos Monsiváis y Elena Poniatowska, así como Héctor Aguilar Camín, Salvador Elizondo y Sabina Berman. La sorpresa fue la asistencia del pintor y priísta consagrado José Luis Cuevas. Además, como bien afirmó Víctor Hugo Rascón Banda, presidente de la Sociedad General de Escritores de México, el Consejo Nacional para la Cultura y las Artes -que fue creado por decreto presidencial del gobierno de Salinas- "no funciona como tal, dado que es regido por una sola persona nombrada por el Presidente" (citado por Bertrán). Fox terminó nombrando a Sari Bermúdez, quien organizó la reunión, lo cual creó múltiples protestas de varios grupos de intelectuales. No sólo Bermúdez fue considerada como la menos indicada para ocupar el prestigioso puesto, sino que además llamó la atención que la hermana de Santiago Creel, el entonces Secretario del Gobierno, Dolores Creel, fuera nombrada Coordinadora de la Unidad de Proyectos Especiales del CNCA. Hasta ahora, nada indica que debamos esperar mucho de la presente administración de Felipe Calderón.

Hay, sin embargo, tres elementos problemáticos de la novela que desmantelan o desarticulan los argumentos, denuncias y acusaciones que se hacen de la política cultural en México. El primero tiene que ver con el hecho de que el autor difícilmente se podría considerar como un escritor excluido o marginado. Serna es uno de los

Revista Iberoamericana, Vol. LXXVI, Núm. 231, Abril-Junio 2010, 393-407
ISSN 2154-4794 (Electrónico) 
“jóvenes” escritores más conocidos en el país -a pesar de que él mismo insiste en entrevistas y conferencias en presentarse como un escritor fuera del sistema, al estilo de sus personajes álterego, Roberto Lima y Evaristo Reyes ${ }^{5}$ y es un colaborador frecuente de Letras Libres y Nexos y que publica en Joaquín Mortiz y CONACULTA.

El segundo elemento que desarticula el proyecto de la novela tiene que ver con el triunfo literario del protagonista, quien gana, “a la buena”, el premio de novela "Eureka”, sobre todo porque la obtención de este premio es precisamente el móvil que lleva al verdadero asesino a confesar su crimen. Resulta incongruente que después de atacar y cuestionar la integridad del proceso editorial de los jurados y editores (y de lograr que el lector acepte estas premisas), el premio recibido por Evaristo sea el resultado de la "buena calidad" de la novela. Así lo afirma el protagonista cuando el asesino Rubén Estrella le recrimina haberlo planeado “todo muy bien”.

-Gané a la buena -se defendió Evaristo-. No hice ningún arreglo con nadie.

-Que te lo crea tu chingada madre. Todo es parte de un lanzamiento de marketing. En esos premios ya se sabe de antemano quién va a ganar. (267)

En este caso, el humor negro y el tono sarcástico de la obra no pueden utilizarse para justificar tal inconsistencia conceptual y formal.

El tercer aspecto -el más problemático- está relacionado con el hecho de que el asesino, Rubén Estrella, sea uno de los llamados “arribistas” o advenedizos que se han colado con hipocresía y servilismo en el ámbito sublime de la casta divina. Este aspecto es de vital importancia para nuestra discusión, ya que dichos términos ("arribista” o "advenedizo") enmascaran el trasfondo de tensión entre cuestiones de clase asociadas con cuestiones de raza y origen étnico. Tanto Rubén Estrella como sus íntimos amigos, Daniel Nieto y Pablo Segura, son descritos en la novela como arribistas que no pertenecen verdaderamente a la élite cultural. En la primera descripción del personaje, el narrador nos dice, "Era evidente que venía de muy abajo y se había integrado con dificultades a un medio elitista” (85). Más tarde, lo describe como un hombre de "cara morena y huesuda" como el rostro de un “ídolo tallado en piedra” (129). La dicotomía presentada en la novela de Serna, como en la de Piazza, parece apuntar solamente hacia un conflicto de clases, de estatus social, pasando por alto el trasfondo étnico del conflicto. A fin de cuentas, para ambos escritores, la tensión existe solamente entre los aristócratas de la cultura y los advenedizos y arribistas de otras clases sociales. La novela, por lo tanto, no

5 En varias entrevistas Serna se presenta como un escritor que no pertenece al medio literario, aunque reconoce que ahora sí "se dedica de lleno a la literatura" ya que es colaborador frecuente de Nexos y Letras Libres (Sánchez). Ver también la entrevista con Jorge Luis Herrera.

Revista Iberoamericana, Vol. LXXVI, Núm. 231, Abril-Junio 2010, 393-407 ISSN 0034-9631 (Impreso) ISSN 2154-4794 (Electrónico) 
logra alcanzar su propósito de destruir o desmitificar a esa "casta divina”, y lo que hace en su lugar, paradójicamente, es reforzar precisamente la misma dicotomía que presenta Piazza entre los que sí pertenecen y los que no son legítimos miembros de la República de las Letras, ya que el asesino del único escritor que vale la pena en México es uno de estos arribistas que en la obra han sido reducidos a una camarilla de pícaros que, al estilo del Lazarillo de Tormes, sólo buscan arrimarse a buen puerto y recoger las migajas del banquete de los dueños de la cultura. Además, Serna no parece darse cuenta de que la política cultural en México no tiene que ver-como sugiere uno de sus personajes al inicio de la novela- con el simple hecho de que "los políticos no saben quién es quién en el mundo de la cultura y se dejan guiar por las apariencias" (88) o que las decisiones político-culturales (quién recibe un nombramiento o determinado premio literario, beca o puesto consular) no tienen nada que ver con el talento o la calidad, sino con cuestiones de raza y origen étnico, las que obedecen a una visión eurocéntrica de la cultura. Como dice Jill Robbins, un resultado de este prejuicio "is the impetus on the part of Latin American mestizos to prove that they are, in fact, European, an anxiety that often leads to extreme discrimination against indigenous people” (97).

Para nuestro estudio, éste es uno de los aspectos más importantes de la novela de Serna, pues nos sirve para develar lo que consideramos un aspecto sumamente complejo de la cultura mexicana en cuanto a las diferencias étnico-raciales y que están íntimamente ligadas a la política cultural del país. En el imaginario nacional, el tema del racismo es un tema que supuestamente no tiene nada que ver con nuestra cultura, ya que se acepta a priori que nosotros los mexicanos no somos racistas. El racismo es un tema tabú del que sólo se habla en términos de la otredad, como algo que existe y se da fuera del país y sólo contra los negros: en los EE.UU., en Europa o en Sudáfrica. Un ejemplo de esta inconciencia racial sería la controversia en México y en los Estados Unidos, provocada en junio de 2005, por la publicación conmemorativa de una serie de estampillas de un famoso personaje de cuentos, llamado Memín Pinguín. En el país del norte, el debate se centraba en la descripción exagerada de los rasgos faciales de Memín Pinguín y su asociación con el infame personaje Sambo de la cultura estadounidense y que remite a los años de represión y discriminación abierta. Semanas antes, el Presidente Vicente Fox había dicho públicamente que los inmigrantes mexicanos en los Estados Unidos hacían los trabajos que "ni siquiera los negros americanos harían”, ofendiendo así no sólo a los estadounidenses de origen africano, sino también, y sin darse cuenta, a los mismos "paisanos" que supuestamente pretendía defender. De hecho, el término "paisano", como "arribista” o "advenedizo", está fuertemente ligado con el origen mestizo o indígena del campesino. El término "paisano”, por ejemplo, jamás sería utilizado para referirse a un inmigrante mexicano en EE.UU., o en el extranjero,

Revista Iberoamericana, Vol. LXXVI, Núm. 231, Abril-Junio 2010, 393-407
ISSN 2154-4794 (Electrónico) 
de origen blanco o europeo. Este comentario del presidente mexicano provocó la crítica de líderes y activistas afro-americanos como Jesse Jackson y Al Sharpton, así como la misma Casa Blanca, que repudió el comentario racista del gobierno mexicano. Curiosamente, el debate en México se centró más en cuestiones de soberanía y patriotismo que, específicamente, en la discriminación de los negros -mexicanos o extranjeros- en México. Tampoco se identificó el otro insulto, más sutil y corrosivo, el insulto encubierto contra los "paisanos" que nunca fue condenado, y, por lo tanto, el imaginario nacional evadió lo que pudo haber sido un ejercicio autorreflexivo y autocrítico de la forma en que se manifiesta, en México, la discriminación racial: a través de sutiles códigos de exclusión, utilizados contra individuos de extracción indígena.

La novela de Serna es sintomática del afán de muchos intelectuales en México por alcanzar la deseada "modernidad” a través de la búsqueda y adquisición de una entidad e identidad entendidas como universales. En este sentido, y a pesar de que se proponía otra cosa, de que el proyecto era otro, Serna termina cayendo en la misma trampa que Piazza (y muchos otros escritores mexicanos) al plantear el debate de la cultura en México dentro de un espacio escindido entre la casta divina y los arribistas, reafirmando así la existencia real de una República de las Letras que apunta, casi exclusivamente, hacia la herencia europea blanca y resiste o suprime las otras expresiones multiculturales del país.

En México, el debate sobre la producción cultural generalmente ha oscilado entre el nacionalismo local y el cosmpolitismo universalista, aunque este último ha sido predominante. Como señala Deborah Cohn, refiriéndose a la "Generación de medio siglo", la producción cultural en México ha sido dominada por un grupo de intelectuales que ha buscado "legitmar una definición cosmopolita de la cultura mexicana” "“Construcción” 89-90). Este debate, curiosamente, ha resurgido en las letras mexicanas contemporáneas. La generación de los "Enterradores” (un grupo de escritores nacidos en los años sesenta), a través de dos de sus representantes (Celso Santajuliana y Ricardo Chávez Castañeda), manifiesta en su reciente libro que existe un descentramiento geográfico-psicológico en un número significativo de obras, las que no se focalizan más en México ni en lo mexicano, "ampliando así las coordenadas de lo narrable” (Chávez Castañeda y Santajuliana 130).

Todo esto se complica una vez que tomamos en cuenta otros factores determinantes en el espacio literario mexicano. Los mismos autores de la generación de los "Enterradores" incluyen, entre su serie de prescripciones y consejos a sus seguidores y potenciales futuros escritores, el ser conscientes de que el éxito profesional depende de varios factores que no necesariamente tienen que ver con el talento: uno de éstos es lo que ellos llaman el capital del escritor, que incluye tanto aspectos de clase social y apariencia física, como factores que facilitan el acceso a lo que ellos llaman el espacio de la "Aliteratura pura”:

Revista Iberoamericana, Vol. LXXVI, Núm. 231, Abril-Junio 2010, 393-407 ISSN 0034-9631 (Impreso) ISSN 2154-4794 (Electrónico) 
a) El estilo, el porte, la clase, involucran desde la vestimenta hasta la personalidad y la desenvoltura. Una matemática de las formas [...].

b) La belleza y la apostura dictadas por occidente en la blancura, la esbeltez, la visibilidad estética [...] El molde es omnipotente tanto en esta fiesta donde te has introducido como a la hora de elegir embajadas de narradores para representar a tu país en el extranjero. (Chávez Castañeda y Santajuliana 73)

Más adelante, ofrecen incluso un ejemplo concreto:

El libro de David Miklos Una ciudad como ésta, con la cual editorial Tusquets México sentó su apuesta sobre la narrativa joven es un claro, visible, esbelto y bello ejemplo de esta mecánica selectiva del álbum fotográfico. (73-74)

Aunque Santajuliana y Chávez no lo dicen abiertamente, no es difícil ver el componente étnico-racial en todo esto. Sin embargo, ellos no parecen percatarse de la implícita contradicción de su postura que, por un lado, desea el desplazamiento de México y lo mexicano en favor de una entidad abstracta y universal, por un lado y, por el otro, implica el rechazo de varios escritores de México debido a factores de clase y raza. Lo que falta en este debate, como en el caso de la novela de Serna, es reconocer o ser consciente de que cuando en México se habla de una identidad cosmopolita o universal, ésta se entiende como una identidad europea, blanca -lo universal es solamente lo que deviene de la cultura occidental- este eurocentrismo es el punto de partida. Como señala Robert Stam, en su artículo "Eurocentrism, Polycentrism, and Multicultural Pedagogy”, el eurocentrismo es

definable as the procrustean forcing of cultural heterogeneity into a single paradigmatic perspective. Eurocentrism sees Europe as the privileged source of meaning, as the world's center of gravity, as ontological 'reality' to the rest of the world's shadow. (98)

Y aunque eurocentrismo y colonialismo no son necesariamente lo mismo, ambos conceptos van íntimamente ligados:

As an ideological substratum common to colonialist, imperialist and racist discourse, Eurocentrism is a form of vestigial thinking that permeates and structures contemporary practices and representations even after the formal end of colonialism. (Stam 98)

Por otro lado, y como dice Stam, defendiendo una visión multiculturalista, la crítica del eurocentrismo no está dirigida contra los europeos como individuos “but rather to dominant Europe’s historically oppressive relation to its internal and

Revista Iberoamericana, Vol. LXXVI, Núm. 231, Abril-Junio 2010, 393-407 
external 'others'” (99) y puesto que el eurocentrismo "[I]s a historically situated discourse and not a genetic inheritance, Europeans can be anti-Eurocentric, just as non-Europeans can be Eurocentric” (99).

Mas no se trata aquí de atacar Europa per se, sino de relativizar a Europa y lo europeo, viéndolos más bien no como un substrato real, localizado geográficamente, sino como la invención de un espacio ficticio y de un discurso que, por un lado, privilegia una visión idealizada de Europa y, por el otro, suprime, omite, rechaza o devalúa la diversidad cultural y racial de los países periféricos del segundo y tercer mundo incluso la diversidad cultural de la misma Europa, tal es el caso de los gitanos, los judíos, los irlandeses, los inmigrantes turcos y árabes y, en general, las minorías de color más obscuro. Todo esto se debe, como dice Stam, al hecho de que "Eurocentrism is the 'normal' view of history that most First Worlders, Second Worlders and even many Third and Fourth Worlders learn at school and imbibe from the media” (100). En otras palabras, lo que nos interesa aquí, tiene que ver menos con las intenciones individuales de un escritor que con la serie de discursos institucionalizados, la pedagogía del eurocentrismo, que históricamente han configurado las relaciones de poder y han promulgado la idea de que lo europeo es lo universal.

Este concepto eurocéntrico de universalismo es de interés especial para la crítica poscolonial, porque es la noción de una naturaleza humana homogénea y unitaria la que excluye, por “no universal”, a la producción cultural de sociedades periféricas. El debate no es si existe o no una esencia humana común a todos los seres vivos, sino si la apropiación de una determinada construcción de universalismo es utilizada con el fin de ejercer control y dominio sobre el producto cultural y artístico. De acuerdo con Chinua Achebe, "[T] he universalist myth has [...] a pernicious effect in the kind of colonialist criticism which denigrates the post-colonial text on the basis of an assumption that 'European' equals 'universal'” (citado por Ashcroft 55). Por su parte, Bill Ashcroft aclara que:

The assumption of universalism is a fundamental feature of the construction of colonial power because the "universal" features of humanity are the characteristics of those who occupy positions of political dominance. It is these peoples who are the 'human', who have a legitimate history, who live in 'the world'. (55)

Es a esto precisamente a lo que hace referencia la novela de Serna, pero sin perspectiva ni cuestionamiento. Los constantes comentarios despectivos contra los “arribistas” intelectuales y, en general, contra todos los personajes de extracción indígena-como el Chamula, el escudero de Maytorena que es asesinado a tiros por Evaristo, pero que por "paradojas de la justicia mexicana” su muerte no se le imputa

Revista Iberoamericana, Vol. LXXVI, Núm. 231, Abril-Junio 2010, 393-407 ISSN 0034-9631 (Impreso) ISSN 2154-4794 (Electrónico) 
al protagonista "quizá porque a los ojos de la ley el Chamula era una víctima de segunda” (239); también la eventual criminalización de Rubén Estrella, con su “cara morena y huesuda como de ídolo tallado en piedra” (129)-confirman los prejuicios de clase y el consuetudinario desprecio racial que se ejerce habitualmente contra aquellos individuos de origen humilde, que no pertenecen a la clase privilegiada por no ser los suficientemente blancos - una especie de jerarquía del color. De esta forma, y aunque el autor se ha propuesto la desmitificación de esa "casta divina", el locus de enunciación del texto, paradójicamente, se encuentra dentro de ese espacio que tan acerbamente critica el autor, validando y legitimando su existencia. Y aunque Serna denuncia las prácticas de exclusión de la mafia intelectual y Piazza las justifica y defiende, ambos autores coinciden en su rechazo de los "arribistas", en sus prejuicios raciales: condenan a los personajes de extracción indígena, no europea, al servilismo, al fracaso o al crimen -una visión bastante limitada de la riqueza y diversidad cultural de México. El valor de la novela radica, entonces, en el despliegue de esta compleja dinámica sociocultural y racial del país, poniendo en evidencia la profunda crisis intelectual del país, la bancarrota de la cultura y el fracaso del Estado en lograr una verdadera y auténtica democratización de la cultura -algo que no se podrá lograr mientras que la visión eurocéntrica y la jerarquía del color sigan siendo la vara con que se mide y se sustentan las decisiones oficiales, ignorando o rechazando la contribución de otros grupos alternativos de producción cultural en el país.

\section{Bibliografía}

Anderson, Danny. “Creating Cultural Prestige. Editorial Joaquín Mortiz”. Latin American Research Review 31/2 (1996): 3-41.

Ashcroft, Hill, Gareth Griffiths, y Helen Tifflin, eds. The Post-Colonial Studies Reader. Londres: Routledge, 1995.

Bertrán, Antonio. "Descartan crear Secretaría del Arte”. Reforma. Jueves, 20 de julio de 2000. <http://www.reforma.com/cultura/articulo/0214771>.

Cohn, Deborah. "La construcción de la identidad cultural en México: nacionalismo, cosmopolitismo e infraestructura intelectual, 1945-1968”. Foro Hispánico, El laberinto de la solidaridad. Cultura y política en México (1910-2000) (2002): 89-103. Kristine Vanden Berghe y Maarten van Delden, eds. <http://www.ingentaconnect.com/search/expand?pub=infobike://rodopi/ foro/2002/00000022/00000001/art00006\&unc $=>$

"The Mexican Intelligentsia, 1950-1968: Cosmopolitanism, National Identity, and the State”. Mexican Studies / Estudios Mexicanos 21/1 (Winter 2005): 141-82.

Revista Iberoamericana, Vol. LXXVI, Núm. 231, Abril-Junio 2010, 393-407
ISSN 2154-4794 (Electrónico) 
Chávez Castañeda, Ricardo y Celso Santajuliana. Lageneración de los enterradores. Una expedición a la narrativa mexicana del tercer milenio. México: Nueva Imagen, 2000.

Cummings, Milton C., Jr. y Richard Katz, eds. The Patron State. Government and the Arts in Europe, North America and Japan. New York: Oxford UP, 1987.

Fernández Retamar, Roberto. "Sobre la penetración intelectual del imperialismo yanqui en América Latina”. Casa de las Américas 6 (nov.-dic., 1966): 13339.

García Canclini, Néstor, coord. Reabrir espacios públicos. Políticas culturales y ciudadanía. México: Universidad Autónoma Metropolitana Unidad Ixtapalapa y Plaza y Valdés, 2004.

Garretón, Manuel Antonio, coord. El espacio cultural latinoamericano. Bases para una política cultural de integración. Santiago: Fondo de Cultura Económica, 2003.

Herrera, Jorge Luis. Entrevista con Enrique Serna. <http://www.sepiensa.org.mx/ contenidos/2004/serna/serna_1.htm>

Jones, D.J.H. Murder at the MLA. Athens y London: The U of Georgia P, 1993.

Pacheco, José Emilio. Las batallas en el desierto. México: Era, 1981.

Piazza, Luis Guillermo. La mafia. México: Joaquín Mortiz, 1968.

Robbins, Hill. “Globalization, Publishing, and the Marketing of 'Hispanic' Identities”. Iberoamericana 3/9 (2003): 89-101.

Revista Iberoamericana. Mercado, editoriales y difusión de discursos culturales en América Latina LXVII/197 (octubre-diciembre 2001).

Sada, Daniel. "Panorama de la literatura mexicana hacia el siglo XXI". Conferencia magistral, sesión de clausura VIII Jornadas Metropolitanas. Ciudad de México, 4 de julio, 2001.

Sánchez, Carlos. "La obsesión por el éxito puede ser destructiva”. Entrevista con Enrique Serna. <http://www.elritmodelvolchevique.blogspot.com/2005/10/ entrevista-con-enrique-serna.html>

Serna, Enrique. El miedo a los animales. México: Joaquín Mortiz y Planeta, 2001.

Stam, Robert. "Eurocentrism, Polycentrism, and Multicultural Pedagogy: Film and the Quincentennial”. Late Imperial Culture. Román de la Campa, E. Ann Kaplan y Michael Sprinkler, eds. Londres: Verso, 1995. 97-121.

Young, Robert J.C. White Mythologies. Londres: Routledge, 2004.

Revista Iberoamericana, Vol. LXXVI, Núm. 231, Abril-Junio 2010, 393-407 
